\title{
(2) OPEN ACCESS \\ Triage and resuscitation tools for low and middle income countries: how to catch the killer?
}

\author{
Indumathy Santhanam, ${ }^{1}$ Prinetha Moodley, ${ }^{2,3}$ Balaji Jayaraman, ${ }^{4}$ \\ Adriana Yock-Corrales, ${ }^{5}$ Baljit Cheema, ${ }^{6,7}$ Simon Craig (D) , 8,9 \\ Haiko Kurt Jahn (D) 10,11
}

- Additional supplemental material is published online only. To view, please visit the journal online (http://dx.doi. org/10.1136/archdischild2021-321981)

For numbered affiliations see end of article.

\section{Correspondence to}

Dr Haiko Kurt Jahn, Children's Emergency Department, Gold Coast University Hospital, Southport, QLD BT12 6BE, Australia; haiko.jahn@doctors. org.uk

Received 6 March 2021 Revised 22 April 2021 Accepted 27 April 2021
Check for updates

(c) Author(s) (or their employer(s)) 2021. Re-use permitted under CC BY-NC. No commercial re-use. See rights and permissions. Published by BMJ.

To cite: Santhanam I,

Moodley $\mathrm{P}$, Jayaraman $\mathrm{B}$,

et al. Arch Dis Child Educ

Pract Ed Epub ahead of

print: [please include Day

Month Year]. doi:10.1136

archdischild-2021-321981

\begin{abstract}
Under-5 mortality rates in low and middleincome countries (LMIC) remain high. One major contributing factor is the failure to recognise critically unwell children when they first present to hospital. This leads to delayed or inadequate resuscitation and an increased risk of death. Triage is a key skill in this setting to sort the queue and prioritise patients, even when staff and equipment are scarce. In LMIC, children generally present late in their illness and often have progressed to some degree of multiorgan dysfunction.

Following triage, a structured systematic primary survey is critical to ensure the detection of subtle signs of multiorgan dysfunction. Repeated physiological assessments of the child guide subsequent resuscitation management decisions, which depend somewhat on the resources available. It is possible to achieve significant improvements in survival of critically unwell children presenting for emergency care in the resource-limited setting. The three key steps in the patient's journey that we can influence in emergency care are triage, primary survey and initial stabilisation. Resources that address these steps have been developed for all settings. However, these resources were developed in a specific clinical context, and must therefore be adapted to local structures and processes. A systematic approach to triage and resuscitation saves lives.
\end{abstract}

\section{INTRODUCTION}

Under-5 mortality rates in low and middleincome countries (LMIC) still remain high, with many children dying from diarrhoeal disease and lower respiratory tract infections. ${ }^{12}$ Over $30 \%$ of deaths occur in the first 24 hours of hospital admission. ${ }^{3}$ Preventable illness and failure to recognise critically unwell children when they first present have been highlighted as major contributing factors. ${ }^{45}$
Acutely unwell children can develop life-threatening organ dysfunction, which can go unrecognised by their caregiver and medical staff. Early recognition at the time of presentation to health services is key to initiate the appropriate emergency treatment and may lead to reduced mortality. Internationally endorsed standards for paediatric emergency care have been developed and are a vital tool to improve the quality of care. ${ }^{6}$

Emergency care in LMIC is unpredictable, fast paced and demanding, yet has the potential to make a significant impacts on health outcomes of critically ill children. ${ }^{45}$ Access to healthcare facilities is limited. Patients and families will often have to travel long distances, which results in delayed presentations. For example, in status epilepticus, the median time of seizure duration prior to hospital arrival was $45 \mathrm{~min}$ with virtually no deaths in Australia and New Zealand, ${ }^{7}$ whereas in India the median time of seizure duration prior to hospital arrival was $172 \mathrm{~min}$ and the mortality rate was $4.6 \%{ }^{8}$ The limited number of healthcare facilities in lowresource settings also results in long queues of patients waiting to be seen. It is therefore critical to have a way of rapidly recognising children who require urgent resuscitation.

\section{Case introduction}

You have decided to take time out of your current position and volunteer in an LMIC. You ask yourself: Why do children not respond in the same way to medical intervention as in HICs? What can be done to ensure better outcomes for unwell and critically ill children in resource-limited settings?

The basic principles of management of airway, breathing and circulation management, the $\mathrm{ABCDE}$ approach remains the 
same in all settings. However, 'standard' treatment extrapolated from high-income settings may sometimes have unexpectedly negative results. For example, a study of over 3000 children in Uganda, Tanzania and Kenya with severe febrile illness and impaired perfusion found that fluid bolus therapy was associated with significantly higher mortality, ${ }^{9}$ challenging the accepted wisdom from high-income countries (HIC) of repeated fluid boluses in sepsis.

The ABCDE approach is not a 'one-size-fits-all' solution. It must be adapted to the clinical context and the practice environment. For example, in trauma, this requires early attention to major haemorrhage. The 'zero-point survey' in trauma includes preparation prior to the patient's arrival and emphasises the need for team preparation and leadership, and anticipation and management of complications. ${ }^{10}$ In LMICs, adapting the primary survey to not only recognise and treat obvious life threats, but also to identify subtle signs of organ dysfunction, is critical. As these findings will influence ongoing management decisions and aid rapid recognition of children with pre-terminal 'normalisation' of previously abnormal vital signs.

In the LMIC setting, the standard ABCDE approach needs to be further adapted to reflect local disease patterns and available resources. ${ }^{11}$

A team approach to these critically unwell patients may be challenging in resource-poor settings. Triage, followed by a structured primary survey (designed to detect subtle signs of multisystem organ dysfunction) and a structured summary of these findings to formulate a holistic management plan, based on the available resources, may be key to improved survival (box 1). ${ }^{12}$

\section{TRIAGE}

Effective triage is key to identifying the critically unwell child on arrival, and has been shown to save lives. ${ }^{4} 13$ However, recognising a sick child can be challenging in any setting. Those working in LMIC face a number of difficulties: overcrowding, late presentation, absence of equipment, understaffing and patient risk factors including dehydration, malnutrition, malaria and/or severe developmental problems due to neonatal complications. ${ }^{4}$ There is often a lack of senior support, such as paediatricians, anaesthetists and intensivists, on-site.

Box 1 Patient journey adapted from zero-point survey in trauma (adapted from Reid et a $\left.\right|^{10}$ )

1. Pre-arrival—-prepare staff and appropriate resources.

2. Arrival-triage (emergency, priority, wait).

3. Initial assessment (primary survey) - to rule in life threats and subtle signs of organ dysfunction.

4. Summarise findings and formulate resuscitation plan.

5. Emergency treatment-resuscitation with the available resources.

6. Reassessment and monitoring for complications.

7. Disposition and convalescence- home or inpatient ward.

\section{Case 1}

Bonginkosi is a 2-year-old boy. He has had diarrhoea for the last couple of days and is lethargic with sunken eyes. He arrives with his grandmother at the clinic and joins the queue.

The WHO developed Emergency Triage Assessment and Treatment (ETAT), a triage system designed for LMIC settings, which takes these difficulties into account. ${ }^{14}$ ETAT can be taught to anybody, from frontline medical to lay staff, to help identify critically unwell children. ${ }^{15}$ It triages children into three categories (emergency, priority and wait). It is the current standard of care in Africa and other LMIC settings. ${ }^{14-16}$ In 1995, the WHO and UNICEF launched the Integrated Management of Childhood Illness (IMCI), which provides nurse practitioners comprehensive evidence-based management guidelines for children in LMIC. The IMCI guidelines have been integrated with ETAT in some settings. ${ }^{17}$

\section{Case 1 continued}

Bonginkosi is showing signs of dehydration (sunken eyes, lethargy). Using ETAT, he is triaged as an emergency.

The ETAT triage tool has been further developed in East Africa to the ETAT+, where the plus stands for plus treatments and includes management algorithms for common paediatric emergency presentations and advice on specific interventions such as oxygen, fluids and glucose control. ${ }^{13}$ These have been adopted to local disease patterns and prevalence in different countries and integrate both local and WHO guidance. ${ }^{16}$

\section{Case 1 continued}

As ETAT+ is used at the healthcare facility that Bonginkosi attends, oral rehydration solution is commenced according to the local protocol, which he tolerates.

Triage systems validated in the paediatric population in HIC settings include the Australasian Triage Scale, the Canadian Triage and Acuity Scale, the Manchester Triage System and the Emergency Severity Index. ${ }^{18}$ They allocate patients to one of five levels. A common limitation of these aggregated triage systems is that they were not designed for the LMIC setting, and their failure to recognise inherent risk factors specific to these settings as previously outlined.

An example of an aggregated triage systems developed for these settings is the South African Triage Scale for children, however the practical application can be challenging in the busy resource-limited settings. ${ }^{9} 1618$

In Tamil Nadu, India a stepwise approach designated as Pediatric Resuscitation and Emergency Medicine (PREM) is used. The word 'PREM' means 'affection' in Sanskrit. PREM was initially developed to screen febrile children for life-threatening organ dysfunction (online supplemental appendix 1). ${ }^{12}$

Step 1 of the PREM approach comprises a series of focused questions to screen children waiting in the 
queue for early subtle signs of hypoxia, shock, cardiovascular dysfunction or non-convulsive status epilepticus (NCSE). ${ }^{12}$ See table 1 for a comparison of the ETAT and PREM triage approach.

\section{PREM triage questions with rationale}

\section{Primary complaint: Fever with or without a clear focus}

Ask if there has been any altered level of consciousness or breathlessness during this illness:

Altered level of consciousness?

Infant: incessant cry? Lethargy? Not his usual self? More sleepy than usual?

Child: agitation? combativeness?

Fever + altered level of consciousness $=$ septic shock Breathlessness?

- Episodic? Or since birth? (to rule out asthma, recurrent aspiration and congestive heart failure or chronic lung disease).

Fever + altered level of consciousness + first acute episode of breathlessness

= septic shock with possible pulmonary oedema due to acute lung injury or cardiac dysfunction

Adapted from the National Health Mission-Strengthening of Pediatric Emergency Care System in Tamil Nadu-Establishment of Pediatric Resuscitation and emergency Units under Tamil Nadu Accidents and Emergency Care Initiative under the name of PREM G.O(D)No. 539, Department of Health and Family Welfare, dated 30 November 2019.

\section{Case 2}

Ram is 12 months old. His mum says that Ram has had fever for the past 2 days and has been crying inconsolably since the previous night. This morning he became sleepier than usual and has developed fast breathing. He is normally well, with no major comorbid conditions.

\section{Triage of case 2 (table 1)}

\begin{tabular}{|c|c|}
\hline ETAT triage & PREM triage \\
\hline $\begin{array}{l}\text { Lethargy (sleepier } \\
\text { than usual) } \\
\text { Respiratory } \\
\text { Distress (fast } \\
\text { breathing) }\end{array}$ & $\begin{array}{l}\text { Fever (with cough, diarrhoea or any other } \\
\text { focus?) } \\
\text { 1. fever for the last } 2 \text { days } \\
\text { Altered level of consciousness? } \\
\text { 1. Inconsolable cry } \\
\text { 2. Sleepy } \\
\text { 3. Lethargy } \\
\text { First acute episode of Breathlessness (not } \\
\text { episodic, not chronic?) } \\
\text { 1. fast breathing }\end{array}$ \\
\hline Emergency & $\begin{array}{l}\text { Fever }+ \text { altered level of consciousness }+ \text { first } \\
\text { acute episode of breathlessness } \\
=\text { septic shock with possible pulmonary } \\
\text { oedema due to acute lung injury or cardiac } \\
\text { dysfunction }\end{array}$ \\
\hline
\end{tabular}

ETAT, emergency triage assessment and treatment; PREM, pediatric resuscitation and emergency medicine.

\section{PRIMARY SURVEY}

Even in HIC, the assessment of the unwell child can be challenging. This has led to initiatives such as 'Spotting the Sick Child' (https://spottingthesickchild.com). ${ }^{19}$ This initiative arose out of the realisation that the assessment of sick children is different to adults and many health professionals are anxious about assessing sick children.

The Paediatric Assessment Triangle (PAT) is a hands-off evaluation to assess the physiological status of a child in less than 30 seconds, endorsed by the American Academy of Paediatrics. It has been validated as a powerful tool for quickly identifying the severity of illness in children in emergency care and prehospital settings. The PAT's three sides stand for general appearance, breathing and cardiovascular status. $^{20}$

Advanced Life Support Courses teach a primary survey to rule in life threats using a team approach. ${ }^{1121}$ This is followed by a more detailed secondary survey once these have been addressed. ${ }^{22}$ This approach may lead to subtle signs of organ dysfunction being missed on the inital primary survey with the potential to lead to detrimental resuscitation decision being made. This is especially relevant in settings where children present late and or already have developed subtle multiorgan dysfunction at presentation. An example would be a child presenting with seizures secondary to hypoxia and sepsis (as opposed to seizures caused by sudden abnormal electrical discharges in the brain or a primary brain pathology). Standard status epilepticus management, with failure to recognise the subtle signs of multiorgan dysfunction and sepsis at initial presentation and failure to concurrently optimise all organ systems could be fatal in this presentation. ${ }^{12}$ Examination to detect subtle signs of NCSE (non-convulsive status epilepticus) is part of the PREM assessment. ${ }^{12} 23$ Detrimental outcomes can also be seen with overzealous fluid bolus therapy. ${ }^{9} 1213$

\section{Case 2 continued (modified Rapid Cardio-Pulmonary Cerebral Assessment)}

Ram's airway is unstable as he is not vocalising, and you can hear grunting when you count his respirations (60/ $\mathrm{min})$. You note retractions and an abdominal pattern of respiration. Auscultation reveals crepitations. His heart rate is 120 beats per minute (BPM), heart sounds are not clearly heard. There is no gallop. His peripheries are warm, femoral and dorsalis pedis pulses are of equal strength. The sole of his foot is bright pink, and capillary return (CRT) is rapid. His liver is firm with a liver span of $8 \mathrm{~cm}$ (enlarged). Ram is responsive to pain, but his tone and posture is floppy. His eyes have conjugate gaze with nystagmus. Pupils are responding equally to light. His systolic blood pressure (SBP) was $90 \mathrm{~mm} \mathrm{Hg}$ and his diastolic blood pressure was $0 \mathrm{~mm} \mathrm{Hg}$ (Korotkoff sounds were heard until the end). 
Step 2 of PREM advocates a primary survey that employs a 60-second modified Rapid CardioPulmonary Cerebral Assessment (online supplemental appendix 2: mRCPCA). ${ }^{8}$ The modifications include evaluation for gallop; quality of heart sounds; liver span; comprehensive non-invasive blood pressure assessment (ie, systolic and diastolic pressures, pulse pressure and mean arterial pressure (MAP)), and eye signs of NCSE (online supplemental appendix 3: PREM chart)). These clinical findings were incorporated around the PAT and renamed as the PREM triangle (online supplemental appendix 4: PREM triangle). ${ }^{12}$

In the PREM system, vital signs are interpreted as follows: increased, normal, relatively low or low. This approach was developed since the standard primary survey failed to detect the subtle signs of multiorgan dysfunction, which are frequently seen in LMIC settings, from causes such as pulmonary oedema, cardiovascular dysfunction and NCSE.

Among the most difficult cases to identify are those where there is a subtle discrepancy between what would be expected and that which is seen. Often with vital sign parameters appearing to be better than expected. For example, in an infant with a history of severe gastroenteritis presenting with hypovolaemic shock, a heart rate within the normal range should be interpreted as relative bradycardia. This is an ominous sign that compensatory mechanisms have been exhausted. Similarly, in a child with severe pneumonia, a normal or low-normal respiratory rate for age should raise the suspicion of imminent respiratory failure.

In the resource-limited setting, the ability to detect subtle signs of organ dysfunctions during primary survey allows the resuscitation plan to be modified accordingly. This, combined with knowledge of local disease patterns, complications of management protocols and side effects from treatments, facilitates rapid optimisation of the critically unwell child prior to admission. This strategy can potentially improve child survival. ${ }^{12} 24$

\section{SUMMARY AND PLAN Case 2 continued}

You wonder what the best way to summarise Ram's assessment findings to formulate a holistic management plan with the resources available to you.

Different tools have been developed to summarise clinical findings during resuscitation. A well-run emergency response ensures that all information is taken into account. In many tools, following the completion of the primary survey, the team leader asks for an update from the team to rule in all immediate life threats detected. This creates a shared mental model with all team members and allows team members to voice any concerns that may have. ${ }^{1011}$ The immediate life threats are then addressed, and a secondary survey is performed.

Step 3 in the PREM approach summarises the findings from the focused history and the mRCPCA (performed instead of the primary survey). The individual variables are recorded on a structured template and then collated around the PREM triangle, to understand the physiological status holistically (online supplemental appendix 3, table 2). The advantage of this approach is the ability to detect subtle signs of organ dysfunction prior to the start of resuscitation and guide subsequent management decisions depending on the resources available. In Tamil Nadu, the implementation of the PREM approach has contributed to reduce post-neonatal under-5 mortality in children presenting for emergency care. ${ }^{24}$

\section{Case 2 continued: Table 2 Ram's PREM triangle}

\begin{tabular}{|c|c|}
\hline \multirow[t]{2}{*}{$\begin{array}{l}\text { Disability: Responsive } \\
\text { to pain } \\
\text { Tone and posture: } \\
\text { abnormal } \\
\text { Eyes: conjugate } \\
\text { deviation+nystagmus+, } \\
\text { no lid twitch, pupils } \\
\text { equal and reactive to } \\
\text { light }\end{array}$} & $\begin{array}{l}\text { Airway: unstable } \\
\text { Breathing: RR } 60 \text { BPM, } \\
\text { grunt+, no stridor, } \\
\text { retractions+, abdomino- } \\
\text { thoracic respiration+, } \\
\text { bilateral air-entry+, } \\
\text { crepitation+ }\end{array}$ \\
\hline & $\begin{array}{l}\text { Circulation: heart rate } \\
120 \text { BPM } \\
\text { Heart sounds: } \\
\text { muffling+, no gallop, } \\
\text { warm peripheries } \\
\text { Pulses: ++++/+++, } \\
\text { flushed, CRT }<2 \mathrm{~s} \\
\text { Liver } 5 \text { pan: } 8 \mathrm{~cm} \text { firm } \\
\text { SBP: } 90 \mathrm{~mm} \mathrm{Hg} \\
\text { DBP: } 0 \mathrm{~mm} \mathrm{Hg} \\
\text { Pulse Pressure: > } \\
40 \mathrm{mmHg} \\
\text { MAP: } 30 \mathrm{~mm} \mathrm{Hg}\end{array}$ \\
\hline \multicolumn{2}{|c|}{$\begin{array}{l}\text { Summary: physiological status using the PREM triangle } \\
\text { Airway: unstable } \\
\text { Breathing: impending respiratory failure } \\
\text { Circulation: relative bradycardia, vasodilatory shock, cardiac dysfunction, } \\
\text { SBP high, wide pulse pressure, low MAP } \\
\text { Disability: altered level of consciousness, non-convulsive status epilepticus }\end{array}$} \\
\hline \multicolumn{2}{|c|}{$\begin{array}{l}\text { Adapted from the National Health Mission-Strengthening of Pediatric } \\
\text { Emergency Care System in Tamil Nadu-Establishment of Pediatric } \\
\text { Resuscitation and emergency Units under Tamil Nadu Accidents and } \\
\text { Emergency Care Initiative under the name of PREM G.O(D)No. 539, } \\
\text { Department of Health and Family Welfare, dated } 30 \text { November 2019. }\end{array}$} \\
\hline $\begin{array}{l}\text { BPM, beats per minute; } \\
\text { pressure; MAP, mean ar } \\
\text { Emergency Medicine; } R\end{array}$ & $\begin{array}{l}\text {, capillary refill time; DBP, diastolic blood } \\
\text { al pressure; PREM, Pediatric Resuscitation and } \\
\text { spiratory rate; SBP, systolic blood pressure. }\end{array}$ \\
\hline
\end{tabular}




\section{Case 2 continued: consideration for Ram's further management}

Ram has sepsis resulting in impending respiratory failure, relative bradycardia, vasodilatory cardiogenic shock with low MAP and NCSE. Your resuscitation and management plan needs to reflect local resources available to resolve hypoxia, shock, cardiac dysfunction and NCSE, anticipating any side effects of therapy.

Despite vasodilatory shock, he was not tachycardic. Tachycardia, tachypnoea, and high SBP are noted in early hypoxia or shock. As compensatory mechanisms fail, the respiratory rate, heart rate and SBP fall to the normal range for age, before the child collapses with apnoea, bradycardia and low BP.

It is crucial to differentiate the 'real' normal versus 'relative normal'. Vital signs that are within the normal range but associated with profound alerted level of consciousness, respiratory failure and shock are ominous. This combination of findings is indicative of exhausted compensatory mechanisms with a grave risk for abrupt deterioration.

\section{Systems considerations for the management of acutely unwell children}

All approaches, ranging from IMCI, ETAT+, PREM triangle to advanced paediatric life support (APLS) and paediatric advanced life support (PALS) recommend further general management strategies. These depend on local disease patterns and prevalence, availability and access to medication and equipment. It is important to realise that it is the overall systematic and structured approach encompassing triage, primary survey, and a holistic resuscitation and management plan that results in improved outcomes. ${ }^{17}$

The difference in prehospital median seizure duration times and associated mortality in status epilepticus is one example that highlights system difference between LMIC and HIC. ${ }^{8}$ Understanding the capacity, resources and organisational gaps with respect to healthcare provision is key. The Donebedian model highlights the need to address structure, processes and outcome, in order to better understand the local context. ${ }^{25}$ For example, outcomes for emergency care for children may be impacted by structures (lack of a functioning prehospital ambulance service and/or no universal health insurance) and processes (use of clinical algorithms developed in HIC with different patterns of disease). In a high-income setting, mortality is a very rare outcome, leading to an emphasis on readily accessible and broadly applicable measures (such as patient satisfaction), while in the LMIC setting, survival to hospital discharge remains a very relevant target for children seeking emergency care. $^{26}$

The resuscitation of a paediatric patient is a stressful event and prone to errors, which have been found to occur during all aspects of paediatric resuscitation stages. ${ }^{27}$ Cognitive offloading has been recognised to decrease errors, therefore APLS UK and others recommend the use of various aide memoires at the bedside to guide resuscitation. ${ }^{212728}$ This may be especially important for LMIC, when working in a highacuity setting with overcrowding. Examples include various smartphone apps and books which reduce the need to calculate doses at the bedside. ${ }^{21} 2829$

\section{CONCLUSION}

It is possible to achieve significant improvements in survival of critically unwell children presenting for emergency care in the resource-limited setting. The three key steps in the patient's journey that we can influence in emergency care are triage, primary survey and initial stabilisation. Resources that address these steps have been developed for all settings. However, these resources were developed in specific clinical contexts, and must therefore be adapted to local structures and processes. A systematic approach to triage and resuscitation saves lives.

\section{Author affiliations \\ ${ }^{1}$ Pediatric Emergency Medicine, Institute of Child Health and Hospital for Children, Chennai, Tamil Nadu, India \\ ${ }^{2}$ Department of Paediatrics, Paarl Hospital, Paarl, Western Cape, South Africa ${ }^{3}$ Department of Paediatrics, Stellenbosch University Faculty of Medicine and Health Sciences, Cape Town, Western Cape, South Africa \\ ${ }^{4}$ Paediatrics, Government Dharmapuri Medical College, Dharmapuri, Tamil Nadu, India \\ ${ }^{5}$ Emergency Department, Hospital Nacional de Ninos, San Jose, Costa Rica ${ }^{6}$ Department of Paediatrics, University of Cape Town, Rondebosch, Western Cape, South Africa \\ ${ }^{7}$ Paediatric Retrieval, Specialised Paediatric Retrieval Including Neonatal Transfer (SPRINT) Team, Cape Town, South Africa \\ ${ }^{8}$ Emergency Department, Monash Medical Centre Clayton, Clayton, Victoria, Australia \\ ${ }^{9}$ Research, Murdoch Children's Research Institute, Parkville, Victoria, Australia \\ ${ }^{10}$ Emergency Department, Gold Coast University Hospital, Southport, Queensland, Australia \\ ${ }^{11}$ Center of Emergency Medicine, Friedrich Schiller University Jena, Jena, Thüringen, Germany}

Twitter Prinetha Moodley @Prinetha

Contributors IS: original idea, manuscript. PM: triage, African experience. $B J$ : images. AY-C: triage, Latin American experience; review of the manuscript. BC: triage, African experience; review of the manuscript. SC: review of the manuscript. HKJ: manuscript, case scenario.

Funding The authors have not declared a specific grant for this research from any funding agency in the public, commercial or not-for-profit sectors.

Competing interests None declared.

Patient consent for publication Not required.

Provenance and peer review Commissioned; externally peer reviewed.

Supplemental material This content has been supplied by the author(s). It has not been vetted by BMJ Publishing Group Limited (BMJ) and may not have been peer-reviewed. Any opinions or recommendations discussed are solely those of the author(s) and are not endorsed by BMJ. BMJ disclaims all liability and responsibility arising from any reliance placed on the content. Where the content includes any translated material, BMJ does not warrant the accuracy and reliability of the translations (including but not limited to local regulations, clinical guidelines, terminology, drug names and drug dosages), and is not responsible for any error and/or omissions arising from translation and adaptation or otherwise.

Open access This is an open access article distributed in accordance with the Creative Commons Attribution Non Commercial (CC BY-NC 4.0) license, which permits others to distribute, remix, adapt, build upon this work noncommercially, and license their derivative works on different terms, provided the 
original work is properly cited, appropriate credit is given, any changes made indicated, and the use is non-commercial. See: http://creativecommons.org/ licenses/by-nc/4.0/.

\section{ORCID iDs}

Simon Craig http://orcid.org/0000-0003-2594-1643

Haiko Kurt Jahn http://orcid.org/0000-0003-2308-1221

\section{REFERENCES}

1 Castro F, Benavides Lara A, Garcés A, et al. Under-5 mortality in central America: 1990-2016. Pediatrics 2021;147:e2020003442.

2 Sharrow D, Hug L, Liu Y. Levels \& trends in child mortality report, 2020. Available: https://www.unicef.org/reports/ levels-and-trends-child-mortality-report-2020: United Nations Children's Fund

3 McKerrow N, Mulaudzi M. 2Nd triennial report of the Committee on morbidity and mortality in children under 5 years (COMMIC). South Africa: Department of Health, 2014.

4 Robertson MA, Molyneux EM. Triage in the developing world--can it be done? Arch Dis Child 2001;85:208-13.

5 Duke T, Cheema B. Paediatric emergency and acute care in resource poor settings. J Paediatr Child Health 2016;52:221-6.

6 Gutierrez CE, Gausche-Hill M, Lim RK. Standards of care for children in emergency departments: International Federation of emergency medicine agenda for the care of children. West $J$ Emerg Med 2020;21:581-2.

7 Lewena S, Pennington V, Acworth J, et al. Emergency management of pediatric convulsive status epilepticus: a multicenter study of 542 patients. Pediatr Emerg Care 2009;25:83-7.

8 Santhanam I, Yoganathan S, Sivakumar VA, et al. Predictors of outcome in children with status epilepticus during resuscitation in pediatric emergency department: a retrospective observational study. Ann Indian Acad Neurol 2017;20:142-8.

9 Maitland K, Kiguli S, Opoka RO, et al. Mortality after fluid bolus in African children with severe infection. N Engl J Med 2011;364:2483-95.

10 Reid C, Brindley P, Hicks C, et al. Zero point survey: a multidisciplinary idea to step up resuscitation effectiveness. Clin Exp Emerg Med 2018;5:139-43.

11 Lott C, Araujo R, Cassar MR, et al. The European trauma course (etc) and the team approach: past, present and future. Resuscitation 2009;80:1192-6.

12 Santhanam I. Paediatric emergency medicine course (PEMC). 2 edn. New Delhi: Jaypee Brothers Medical Pub, 2013.

13 Prevatt N. Emergency triage, assessment and treatment plus $($ ETAT +$)$ - online learning: royal college of paediatric \& child health, 2020. Available: https:/www.rcpch.ac.uk/resources/ emergency-triage-assessment-treatment-plus-etat-onlinelearning

14 Duke T. New who guidelines on emergency triage assessment and treatment. Lancet 2016;387:721-4.

15 Dekker-Boersema J, Hector J, Jefferys LF, et al. Triage conducted by lay-staff and emergency training reduces paediatric mortality in the emergency department of a rural hospital in northern Mozambique. Afr J Emerg Med 2019;9:172-6.

16 Robertson SK, Manson K, Fioratou E. IMCI and ETAT integration at a primary healthcare facility in Malawi: a human factors approach. BMC Health Serv Res 2018;18:1014.

17 Carai S, Kuttumuratova A, Boderscova L, et al. Review of integrated management of childhood illness (IMCI) in 16 countries in central Asia and Europe: implications for primary healthcare in the era of universal health coverage. Arch Dis Child 2019;104:1143-9.

18 de Magalhães-Barbosa MC, Robaina JR, Prata-Barbosa A, et al. Validity of triage systems for paediatric emergency care: a systematic review. Emerg Med J 2017;34:711-9.

19 Davies FCW. Spotting the sick child [electronic resource] [Great Britain], 2004.

20 Dieckmann RA, Brownstein D, Gausche-Hill M. The pediatric assessment triangle: a novel approach for the rapid evaluation of children. Pediatr Emerg Care 2010;26:312-5.

21 Advanced Life Support Group. Advanced paediatric life support : a practical approach to emergencies. 6 edn. Chichester, West Sussex: Wiley Blackwell, 2016.

22 Corrales AY, Starr M. Assessment of the unwell child. Aust Fam Physician 2010;39:270-5.

23 Christen O. AIDA2 Freediving manual. V1.00 10/2015. AIDA International Freediving, 2015.

24 Commissioner OOTRGC. Sample registration system statistical report, 2018. Available: https://censusindia.gov.in

25 Donabedian A. Evaluating the quality of medical care. 1966 Milbank Q 2005;83:691-729.

26 Hategeka C, Shoveller J, Tuyisenge L, et al. Pediatric emergency care capacity in a low-resource setting: an assessment of district hospitals in Rwanda. PLoS One 2017;12:e0173233.

27 Kozer E, Seto W, Verjee Z, et al. Prospective observational study on the incidence of medication errors during simulated resuscitation in a paediatric emergency department. BMJ 2004;329:1321.

28 Jahn HK, Jahn IHJ, Roland D. Paediatric emergency research in the United Kingdom IeP. prescribing in a paediatric emergency: a PERUKI survey of prescribing and resuscitation AIDS. Acta Paediatr 2020.

29 Thomson F. Paediatric emergency medication book. Aust Prescr 2016. 